\title{
STRESS INOCULATION TRAINING (SIT) ON STATE-TRAIT ANXIETY OF HIGH-STRESS SENIOR COLLEGE STUDENTS
}

\author{
Rachelle A. Bersamin ${ }^{1}$ and Flordeliza C. Posadas ${ }^{2^{\star}}$ \\ ${ }^{1}$ Professor, PhD, San Pedro College and University of the Philippines Mindanao, Davao City, \\ Philippines, rabersamin1@up.edu.ph \\ 2Professor, PhD, San Pedro College, Davao City, Philippines, fposadas86@gmail.com \\ ${ }^{*}$ Corresponding Author
}

\begin{abstract}
This study examined the impact of Stress Inoculation Training (SIT) program on the state-trait anxiety of 57 high-stress senior college students in one of the colleges in Mindanao using purposive sampling and quasiexperimental design with three treatment conditions 1) no training, 2) abbreviated Stress Inoculation Training, and 3) standard Stress Inoculation Training. Measured at three points in time: pre-intervention phase, post-intervention phase, and delayed post-intervention phase, multivariate analysis of covariance (MANCOVA) showed a significant difference between groups on post-intervention state anxiety scores (postSAS) and delayed post-intervention state anxiety scores (delSAS) Wilk's $\lambda .84, F(4,104)=2.45, p=$ .05. Univariate analysis of covariance (ANCOVA) revealed a significant difference in the post-intervention state anxiety scores $F(2,53)=4.78, p=.01$ with adjusted means significantly lower for the abbreviated Stress Inoculation Training group compared with the no training and standard Stress Inoculation Training groups. Multivariate analysis of covariance results further showed no significant difference between groups on the post-intervention trait anxiety scores (postTAS) and delayed post-intervention trait anxiety scores (delTAS) Wilk's $\lambda=.88, F(4,104)=1.79, p=.14$. Overall, results revealed that abbreviated Stress Inoculation Training effectively reduced state anxiety than standard Stress Inoculation Training. However, neither abbreviated Stress Inoculation Training nor standard Stress Inoculation Training effectively reduced trait anxiety. These findings support the efficacy of abbreviated Stress Inoculation Training in reducing state anxiety.
\end{abstract}

Keywords: stress, state-trait anxiety, stress inoculation training, quasi-experimental, senior college students

\section{INTRODUCTION}

The senior year in college is considered a distinct and complex period. It is a phase in a student's life that is marked by a unique constellation of challenges. Senior college students are considered more stressed than any other year level in college (Jimenez, Solon, \& Turban, 2017). Mock board examinations, pre-board reviews, internships, thesis writing, workloads, social expectations, and financial pressures are just among the many sources of stress and anxiety that place a high demand on senior student's ability to cope.

Coping plays a significant role in one's experience of stress and anxiety. Individuals who have the necessary coping skills are likely to lead a healthy life, while those who lack the ability to cope tend to get 
overwhelmed and distressed (Lazarus \& Folkman, 1984, 1987).

According to the Anxiety and Depression Association of America [ADAA], 2019), stress and anxiety have always been mentioned together because anxiety is an emotional reaction to stress. Spielberger (1972) categorized two types of anxiety: state anxiety and trait anxiety. The former is described as transitory because it is environment-dependent while the latter is characterized as relatively enduring or permanent because it is a personality trait that can be subsumed under neuroticism (Eysenck, 1988).

Stress and anxiety have been active areas of research since the beginning of the century, primarily because of its impact on an individual's health and performance. Literature is replete with studies on the factors, nature, causes, and impacts of these variables to individuals (Martinez, 2004; Gandhe, 2014). However, despite the bulk of information available at this point, people's stress level has been reported to have never gone down (Australian Psychological Society [APS], 2014; American Psychological Association [APA], 2015; Malgorzata, Schneider, \& Gonzales, 2009; Hoffman, 2011; Health and Safety Executive, 2018; Velasco, 2013, May 25). Many college students with stress-related mental health problems are now observed to be on the rise (Bueno, 2018; Tomacruz, 2018; Armilla, 2019). Clearly, this indicates that this problem still persists, in fact, becoming increasingly critical. The gap could have been that we failed to translate the knowledge that we have gained into practice.

So far, a lot of promising techniques and programs have been developed and used to address these issues (Klein, 2018; Hersen, 2005; Erford, 2015; Sadigh, 2012; Ratanasiripong, Ratanasiripong, \& Kathalae, 2012; Turner \& Barker, 2013; McClellan \& Hamilton, 2009; Davis, Eshelman, \& McKay, 2000; Gururaja, Harano, Toyotake, \& Kobayashi, 2011; Suinn, 2013). One technique that has been proven effective is the Stress Inoculation Training (SIT) developed by Meichenbaum in the 1980s (as cited in Saunders, Driskell, Johnston, \& Salas, 1996; Meichenbaum \& Deffenbacher, 1988). It is a broad-based cognitive-behavioral intervention that employs multicomponent training arranged in flexible interlocking phases, namely; conceptual or educational phase, skills acquisition and consolidation phase, and application phase (Meichenbaum, 2008; Dobson, 2009). Since its inception, it has been employed successfully in helping individuals cope with various forms of stressors ranging from physical to psychological using various outcome measures. Moreover, it has been applied to various clinical and non-clinical populations, including medical patients (Moses, 1980; Bosmaijian, 1981; Hendrickson, 1983; Warden, 1983; Yepes, 1984; Sax, 1990; Caddick, 1995), students (Lavit, 1982; Chiu, 1983; Blackmore, 1983; Serrano, 1993; Simmons, 1993), teachers (Schmidt, 1982; Guzicki, 1984; Cecil, 1987), nurses (West, 1984; Toloczko, 1989; Admi, 1997), jail, military, and police officers (Johns, 1986; Digliani, 1994; Crago, 1995; Rosmith, 2013; Hourani et al., 2016), and individuals with psychological disorders (McDaid, 2007) and was found to be effective in reducing anxiety and other stress-related conditions with a varying level of efficacy. Interestingly, its efficacy in the school setting has not been extensively explored, especially among senior college students.

To achieve a real gain out of the voluminous data on SIT's efficacy on reducing stress and anxiety, the researcher is motivated to utilize this program to help senior college students learn effective coping skills. The researcher sees the potential of expanding the guidance counseling programs to accommodate and address senior college students' unique needs. Secondly, SIT as a technique has not been widely used in school settings in the Philippines. Literature is short of information about its applicability among Filipino students, specifically senior college students. In this regard, the researcher would like to contribute to the existing body of knowledge relevant to this program's efficacy with respect to this group. Lastly, considering the bulk of students that need to be given care and attention, one-to-one counseling is deemed inefficient to address the needs of a large population. Hence, the researcher sees a need for a technique that is preventive, amenable to a group setting, efficient, and brief. Based on the literature, brief interventions are no longer just considered alternatives or substitutes to traditional approaches (Capuzzi \& Gross, 2013). Nowadays, they are considered viable options. Overall, this background provided the impetus to examine the effects of the abbreviated SIT compared with standard SIT on high-stress senior college students' state and trait anxiety.

\subsection{Theoretical Framework}

The transactional theory of stress and coping (TTSC) by Lazarus and Folkman (1984) provides the foundation for utilizing SIT as a method of intervention to reduce state and trait anxiety of high-stress senior college students. According to TTSC theory, stress is a product of a transaction or interaction among three variables; the person, the environment, and cognitive appraisal. In this transaction process, cognitive appraisal plays a critical role in mediating the person's stress experience. Therefore, the effect that stress has on a person is based more on one's perception of threat, susceptibility, and ability to cope than the experience of the event itself. SIT as a preventive tool educates the person on the nature of stress and how 
to identify stressors in advance and teaches them how to cope with potential stressors in a safe environment. It allows the person to master coping skills and apply them as they are gradually exposed to real or imagined stressors. This inoculation process hypothesized that by gradually exposing a person to a tolerable amount of stress and teaching him or her how to cope with the experience can eventually build a strong resistance to stress in the future.

In this study, SIT is viewed as a preventive technique that can change the physiological, affective, psychological, and neurological systems of the high-stress senior college students; primarily, by working on the students' cognitive processes, thereby influencing the way they would appraise and react to stressors. This program provides the avenue for students to learn in advance how to cope and rehearse how to deal with stressful events or situations. Developing a higher level of ability and mastery to identify and cope with stressful events could increase students' self-efficacy to solve problems, which could lower their anxiety.

\subsection{Conceptual Framework}

This study aimed to determine the effect of the independent variable groups: no training (no_Trng), abbreviated SIT (abbr_SIT), and standard SIT (stan_SIT) on the dependent variables state anxiety and trait anxiety of high-stress college senior students. The no_Trng group did not receive any form of intervention. The abbr_SIT group received phase 2 or skills acquisition component, and phase 3 or application or followthrough component of the standard SIT program while the stan_SIT group received phases 1 or education/conceptualization component, phase 2 or skills acquisition component, and phase 3 or application or follow-through component of the standard SIT program. On the other hand, the dependent variables of this study state anxiety and trait anxiety were measured using the State-Trait Anxiety Inventory by Speilberger (1983). Participants were tested for each outcome measure at three points in time: preintervention, post-intervention, and delayed post-intervention. Overall, this study hypothesized that independently abbr_SIT and stan_SIT intervention programs would affect the state and trait anxiety scores of the high-stress senior college students compared with no training.

\subsection{Statement of the Problem}

This study aimed to examine the effects of abbreviated SIT and standard SIT on state anxiety and trait anxiety of high-high senior college students.

Specifically, the current study sought answers to the following questions:

1. Are there significant differences in the post-intervention state anxiety mean scores (postSAS) and delayed post-intervention state anxiety mean scores (delSAS) between groups (no_Trng, abbr_SIT, and stan_SIT) while controlling for pre-intervention state anxiety mean scores (preSAS) of high-stress senior college students?

2. Are there significant differences in the post-intervention trait anxiety mean scores (postTAS) and delayed post-intervention trait anxiety mean scores (delTAS) between groups (no_Trng, abbr_SIT, and stan_SIT) while controlling for pre-intervention trait anxiety mean scores (preTAS) of high-stress senior college students?

\section{METHOD}

\subsection{Design}

This study employed a quasi-experimental between-group design with three unequal groups. The training program was divided into four stages: stage 1 or pre-intervention testing, stage 2 or intervention implementation, stage 3 or post-intervention testing, and stage 4 or delayed post-intervention testing (26 days after intervention termination). Stage 2 was further divided into three phases based on the SIT framework: the education phase, skills acquisition phase, and application or follow-up phase. The entire training consisted of 18 separate sessions with 18 hours that lasted for three weeks. The education phase had nine (9) sessions, the skills acquisition phase had seven (7) sessions, and the application phase had two (2) sessions. For the abbr_SIT, the education phase was omitted. Therefore, the abbr_SIT group had nine (9) sessions or nine hours of training, while the stan_SIT group received 18 sessions or 18 hours of training. Figure 1 shows the intervention schematic diagram. 


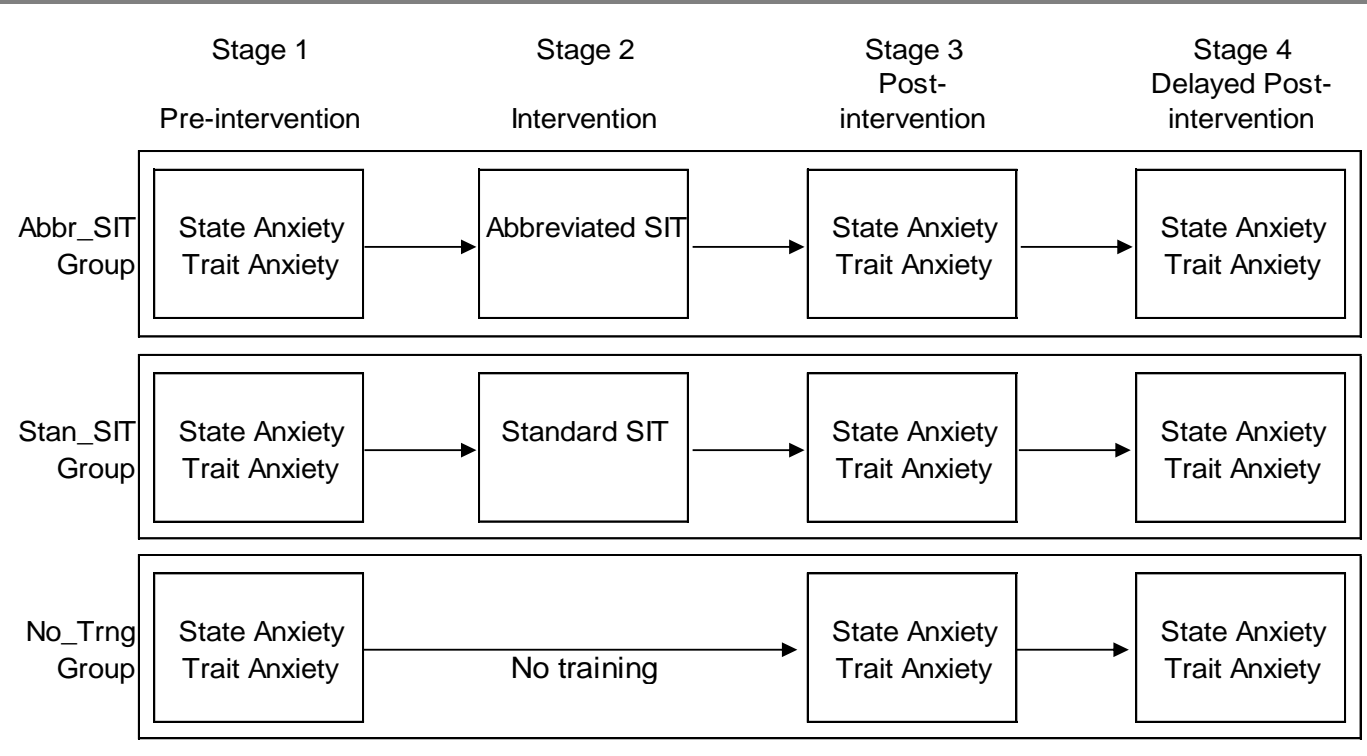

Figure 1. Intervention schematic diagram

\subsection{Participants}

The participants of this study were senior college students from a male-dominated academic program in one of the private colleges in Mindanao. Initially, 69 out of the 90 population volunteered to participate in the study; however, only 57 were considered for the final analysis. Twelve were weeded out due to incomplete data. Of the 57, two (2) were females, and 55 were males. Their mean age is 21.35 , with ages ranging from 19 to 37. Their mean intelligence score is 46.91, as measured by Raven's Advanced Progressive Matrices (APM). Purposive sampling was employed in selecting the participants. Of the four pre-set class sections, three were randomly selected and were used as the basis in determining their assignments to the treatment conditions: no_Trng group $(n=21)$, abbr_SIT group $(n=16)$, and 20 stan_SIT $(n=20)$.

\subsection{Measures}

To measure the dependent variables, trait anxiety and state anxiety, the State-Trait Anxiety Inventory (STAI) by Spielberger (1983) was used. STAI is a standardized self-report inventory based on a 4-point Likert scale. It has two forms, Form $Y$ and Form $X$. Form $Y$ or the State-Anxiety form is composed of statements that measure one's state anxiety or how one feels at the moment. On the other hand, Form $X$ or the Trait-Anxiety form measures one's trait anxiety or how one feels in general. Overall, STAl is composed of 40 questions on a self-report basis with 20 questions for Form $Y$ and 20 for Form X. For each individual, the highest possible score generated from this inventory is 80 , while 20 for the lowest. For the Trait Anxiety scale or Form X, test-retest coefficients are relatively high (.65 to .86) and low for the State Anxiety scale or Form Y (.16 to .62). The internal consistency for both the S-Anxiety (.86 to .95) and T-Anxiety (.89 to .96) scales are relatively high based on alpha coefficients and item-remainder correlations.

\subsection{Ethical Considerations}

Foremost of the ethical considerations were obtaining an informed consent to ensure that the participants understand the whole process and did not participate in the study or intervention against their will. Confidentiality was emphasized during training (Corey, Corey, \& Callanan, 2011), testing, and data collection. The identity of the students and school were also protected. For the participants' benefits, testing and training sessions were all conducted by a licensed psychologist and guidance counselor to see to it that the standard knowledge and skills required to run the program were met. Prior to training, activities were pilot tested at least twice to ensure the quality of the trainer's training and competence. Participants' classes were not disrupted and compromised. To recognize participants' effort and motivate them to complete the whole SIT course, credit points were given by their subject teachers.

\section{RESULTS AND DISCUSSION}

Results showed that the state anxiety mean scores of the senior college students tend to vary between groups at post-intervention testing, especially for the abbr_SIT group $(M=38.06$; $S D=5.53)$ compared to the pre-intervention and delayed intervention between-group mean scores. The abbr_SIT group showed a marked reduction in the state anxiety mean scores between pre-intervention to post-intervention testings. 
However, results showed that the three groups' delayed post-intervention mean scores virtually returned to their pre-intervention level, suggesting that the reduction state anxiety scores were not sustained 26 days after the termination of the SIT program. Table 1 shows the means and standard deviations for state anxiety scores between groups measured at three different testing points.

Table 1. Means and Standard Deviations for State Anxiety Scores between Groups

\begin{tabular}{|l|l|l|l|l|l|l|}
\hline & \multicolumn{2}{|l|}{ Pre-intervention } & \multicolumn{2}{l|}{ Post-intervention } & \multicolumn{2}{l|}{ Delayed Post-intervention } \\
\hline Group & Mean & SD & Mean & SD & Mean & SD \\
\hline No_Trng & 43.19 & 7.83 & 44.48 & 6.99 & 43.38 & 6.76 \\
\hline Abbr_SIT & 40.00 & 6.87 & 38.06 & 5.53 & 41.56 & 5.83 \\
\hline Stan_SIT & 42.75 & 7.45 & 40.75 & 5.50 & 41.45 & 7.33 \\
\hline Overall & 42.17 & 7.43 & 41.37 & 6.54 & 42.19 & 6.67 \\
\hline $\begin{array}{l}n=57 \text { SD = Standard deviation No_Trng = no training Abbr_SIT = abbreviated Stress Inoculation Training stan_SIT = Standard } \\
\text { Stress Inoculation Training }\end{array}$
\end{tabular}

On the other hand, the results of the three groups' trait anxiety mean scores showed no marked variation at the post-intervention testing except for the abbr_SIT group ( $M=43.69$; SD=7.79) compared with the groups' pre-intervention and delayed post-intervention means scores. Results also revealed that between-group mean scores virtually reverted to their pre-intervention levels after as measured 26 days after the SIT program was terminated. Table 2 shows the means and standard deviations for trait anxiety scores between groups measured at three different testing points.

Table 2. Means and Standard Deviations for Trait Anxiety Scores between Groups

\begin{tabular}{|c|c|c|c|c|c|c|}
\hline \multirow[b]{2}{*}{ Group } & \multicolumn{2}{|c|}{ Pre-intervention } & \multicolumn{2}{|c|}{ Post-intervention } & \multicolumn{2}{|c|}{ Delayed Post- intervention } \\
\hline & Mean & SD & Mean & $\mathrm{SD}$ & Mean & SD \\
\hline No_Trng & 46.14 & 6.32 & 47.14 & 6.32 & 46.95 & 6.07 \\
\hline Abbr_SIT & 46.00 & 8.44 & 43.69 & 7.79 & 44.00 & 6.56 \\
\hline Stan_SIT & 47.30 & 6.53 & 47.90 & 5.24 & 48.15 & 5.45 \\
\hline Overall & 46.65 & 7.44 & 46.44 & 6.53 & 46.54 & 6.13 \\
\hline
\end{tabular}

For the impact of SIT on state anxiety, multivariate (MANOVA) analysis showed that there was a significant multivariate effect of the treatment conditions (no_Trng, abbr_SIT, and stan_SIT) on the state anxiety scores (postSAS and delSAS) of the participants Wilk's $\bar{\lambda}=.83, \mathrm{~F}(\overline{4}, 106)=2.57, \bar{p}=.04$, partial $\eta^{2}=.09$. Separate univariate ANOVAs on the dependent variables confirmed a significant main effect for the treatment conditions on postSAS $F(2,54)=5.17, p=.009$ but a not significant main effect on delSAS $F(2,54)=.52, p$ $=.60$. When preSAS was added as covariate in MANCOVA these effect was still significant though a bit weaker Wilk's $\lambda .84, F(4,104)=2.45, p=.05$, partial $\eta^{2}=.09$. Table 3 shows the MANCOVA on postintervention state anxiety scores and delayed post-intervention state anxiety scores between groups. 
Table 3. MANCOVA on Post-intervention State Anxiety Scores and Delayed Post-intervention State Anxiety Scores between Groups

\begin{tabular}{|l|l|l|l|l|l|}
\hline Source & Wilk's $\lambda$ & $\mathrm{df}$ & $\mathrm{F}$ & $\mathrm{p}$ & Partial $\eta^{2}$ \\
\hline Group & .84 & 4,104 & 2.45 & $.050^{*}$ & .09 \\
\hline Covariate (preSAS) & .57 & 2,52 & 19.43 & $.001^{*}$ & .43 \\
\hline${ }^{*} \mathrm{p} \leq .05$ & & & & & \\
\hline
\end{tabular}

Furthermore, two ANCOVAs indicated a significant difference by group on postSAS, $F(2,53)=4.78, p=.01$, partial $\eta^{2}=.15$ but a not significant difference on delSAS, $F(2,53)=.49, p=.62$, partial $\eta^{2}=.02$. Bonferonni post hoc test of the univariate outcomes adjusted for preSAS showed that abbr_SIT group reported a significantly lower postSAS compared with no_Trng group $(p=.02)$ while no significant difference between abbr_SIT and stan_SIT $(p>.05)$. This finding lend support to the efficacy of abbreviated interventions to stress and anxiety. Table 4 shows the ANCOVA on post-intervention state anxiety scores between groups.

Table 4. ANCOVA on Post-intervention State Anxiety Scores between groups

\begin{tabular}{|l|l|l|l|l|l|l|}
\hline Source & SS & MS & df & F & $p$ & Partial $\eta^{2}$ \\
\hline Covariate(preSAS) & 707.15 & 707.15 & 1,53 & 28.73 & $.001^{*}$ & .35 \\
\hline Group postSAS & 235.50 & 117.75 & 2,53 & 4.78 & $.012^{*}$ & .15 \\
\hline${ }^{*} p \leq .05$ & & & & & & \\
\hline
\end{tabular}

Based on the results, the abbreviated SIT shows to be more effective than the standard SIT in reducing senior college students' state anxiety. This result adds to the existing body of findings that provide evidence of the efficacy of abbreviated or brief interventions (Capuzzi \& Gross, 2013). Furthermore, this seems to indicate that the omission of the education phase, which is a cognitive component of SIT, did not affect its ability to reduce the participants' state anxiety. This finding diverges from earlier research, which supported the education component of the SIT program (McCordick, Kaplan, Finn \& Smith, 1979; Harmon-Bowman, 1981). However, it reinforces the claim of Moses (1980) that education component was not a significant component of SIT for it to have an impact on stress or anxiety. On the other hand, the short-term effect of abbreviated SIT could be attributed to the conventional notion of linearity of effect, which suggests that the higher the dose, the longer the effect or, the greater the benefit and vice versa (Howard, Kopta, Krause, \& Orlinsky, 1986; Orlinsky \& Howard, 1986 as cited in Budman \& Gurman, 1988). Consistent with the linearity of effect explanation, the abbr_SIT's impact was not stable over time (26 days) because the number of sessions or duration of exposures was relatively fewer or shorter. In addition, the nature state anxiety which is transitory may play significant role in the stability of the effect of for both abbreviated and standard SIT.

To test the null hypothesis that there are no significant mean differences on postTAS and delTAS between groups (no_Trng, abbr_SIT, and stan_SIT) before covariate adjustment, MANOVA revealed a not significant multivariate effect on the combined dependent variables postTAS and delTAS across groups: Wilk's $\lambda=.91$, $F(4,106)=1.23, p=.30$, partial $\eta^{2}=.04$. Moreover, when preTAS was added as covariate in MANCOVA, the effect was not significant Wilk's $\lambda=.88, F(4,104)=1.79, p=.14$. Table 5 shows the MANCOVA on postintervention and delayed post-intervention trait anxiety scores between groups.

Table 5. MANCOVA on Post-intervention and Delayed Post-intervention Trait Anxiety Scores between Groups

\begin{tabular}{|l|l|l|l|l|l|}
\hline Source & Wilk's $\lambda$ & df & F & $p$ & Partial $\eta^{2}$ \\
\hline Group & .88 & 4,104 & 1.79 & .14 & .06 \\
\hline Covariate preSAS) & .47 & 2,52 & 52.00 & $.001^{*}$ & .53 \\
\hline${ }^{*} p \leq .05$ & & & & & \\
\hline
\end{tabular}

Based on the results, neither abbreviated SIT nor standard SIT shows a significant impact on trait anxiety. This finding confirms the conclusion of Digliani (1994) that there were no significant differences between the 
treatment and control groups on trait anxiety. In addition, this finding can also be linked to the nature of trait anxiety. According to Spielberger (1966), trait anxiety is relatively enduring. Consistent with this definition, trait anxiety is less likely to be affected by any interventions because it is relatively stable. However, the study of Bosmaijan (1981) indicated that SIT could impact trait anxiety at post-treatment. This suggests that further studies can be done on this area as SIT's impact may depend on the characteristics of the subjects involved, their level of anxiety, or duration of treatment.

\section{CONCLUSIONS AND RECOMMENDATIONS}

\subsection{Conclusions}

It is concluded in this study that abbreviated SIT was far more effective than standard SIT in reducing transitory type of anxiety of high-stress senior college students; however, its impact was not stable over time. It can be concluded further that neither abbreviated SIT nor standard SIT was effective in reducing trait anxiety of high-stress senior college students. In this study, the standard SIT failed to impact significantly on both state anxiety and trait anxiety. The abbreviated SIT significantly reduced state anxiety only.

\subsection{Recommendations}

Colleges and universities through the Guidance office can further explore the effectiveness of SIT either in its abbreviated or standard format using a larger sample of students, both males and females, across various levels and academic programs. Once proven applicable, it can be incorporated into the guidance program as a preventive intervention among students, especially in addressing transitory types of stress and anxiety (e.g., mock board examination, examinations, thesis/research, practicums, etc.).

For further research, it is recommended that studies will include examining or evaluating the efficacy of each activity included in the entire SIT program. This current study only focused on the efficacy of SIT's education component, not on the efficacy of each activity within each component. Furthermore, the investigation on abbr_SIT and stan_SIT in combination with other approaches is recommended. This is to examine the possibility of increasing its efficacy when implemented in conjunction with other approaches that are also proven effective.

On the other hand, since this study's sample was taken from a single institution that was relatively small and predominantly males, it is recommended that future research studies consider taking samples from different college institutions and employ a larger sample with males and females population proportionally represented.

This study did not pre-screen the anxiety level of the participants or categorized into levels. Future studies may focus on this aspect to factor in the levels of anxiety (low, moderate, high) of the participants in measuring the impact of abbr_SIT and stan_SIT in reducing stress and anxiety. On the other hand, since SIT is shown to be effective in reducing state anxiety, a temporary type of anxiety, future studies may focus on investigating its impact on a specific source of state anxiety (i.e. mock-board exam) that is transitory.

Finally, since both abbreviated and standard SIT seems to have no impact on trait anxiety but had done so in other studies using different populations, further investigation of this variable on different subjects is recommended.

\section{REFERENCE LIST}

Admi, H. (1997). Stress intervention: A model of stress inoculation training. Journal of Psychosocial Nursing \& Mental Health Services, 35(8), 37-41.

American Psychological Association (2015). 2015 Stress in America. Retrieved from https://www.apa.org/news/press/releases/stress/2015/snapshot

Anxiety and Depression Association of America (2009). Stress. Retrieved from: https://adaa.org/understanding-anxiety/related-illnesses/stress.

Armilla, C. (2019, February 17). College and Mental Health. Inquirer.net. Retrieved February 16, 2019. Retrieved from https://opinion.inquirer.net/103172/college-mental-health

Australian Psychological Society (2014). Australians' stress levels remain high, survey reveals. Retrieved 
from: https://www.psychology.org.au/Search-Results?searchtext=stress\&searchmode=anyword

Blackmore, S. H. (1983). A Comparison of Training in Stress Inoculation, Effective Test Taking Techniques and Study Skills as Treatments for Test Anxiety (Order No. 8329903). Available from ProQuest Dissertations \& Theses Global. (303315552).

Bosmajian, C. P., JR. (1981). A Comparison Of Stress Inoculation Training And Stress Education In The Treatment Of Stress Associated With Dental Procedures (Order No. 8206729). Available from ProQuest Dissertations \& Theses Global. (303151786).

Budman, S. H., \& Gurman, A. S. (1988). Theory and practice of brief therapy. Guilford Press.

Bueno, A. (2018, April 11). Are universities taking care of their students' mental health? CNNphilippines.com. Retrieved from http://cnnphilippines.com/life/culture/2018/04/10/mental-health-issues-university.html

Caddick, N. D. (1995). Reducing emotional distress using the stress inoculation model for HIV-infected people in the pre-AIDS stage (Order No. 9543472). Available from ProQuest Dissertations \& Theses Global. (304229221).

Capuzzi, D., \& Gross, D. R. (Eds.). (2013). Introduction to the counseling profession. Routledge.

Cecil, M. A. (1987). A Comparison of the Effects of Stress Inoculation Training and Coworker Social Support on Teacher Stress (Order No. 8724820). Available from ProQuest Dissertations \& Theses Global. (303633269).

Chiu, M. L. (1993). The influence of anticipatory fear on foreign student adjustment and response to stress inoculation treatment (Order No. 9309580). Available from ProQuest Dissertations \& Theses Global. (304061559).

Corey, G., Corey, M. S., \& Callanan, P. (2011). Issues and ethics in the helping professions Belmont. CA: Brooks/Cole.

Crago, D. A. (1995). The use of stress inoculation training with a military population (Order No. 9524603). Available from ProQuest Dissertations \& Theses Global. (304269263).

Davis, M., Eshelman, E.R., \& McKay, M. (2000). The relaxation and stress reduction workbook. $\left(5^{\text {th }}\right.$ ed.). New Harbinger Publications. Retrieved from https://books.google.com.ph/books?id=aYQIVY64muoC.

Digliani, J. A. (1994). Stress inoculation training: The police (Order No. 9524023). Available from ProQuest Dissertations \& Theses Global. (304109257).

Dobson, K. (2009). Handbook of Cognitive-Behavioral Therapies, Third Edition. Guilford Press. ISBN 1606234382,9781606234389

Eysenck, H.J. (1998). Dimensions of Personality. Transaction Publishing. New Brunswick, New Jersey.

Gandhe, R. J. (2014). Positive stress: Review of relevant theories and an alternative conceptualization. Indian Journal of Positive Psychology, 5(3), 260-266.

Gururaja, D., Harano, K., Toyotake, I., \& Kobayashi, H. (2011). Effect of yoga on mental health: Comparative study between young and senior subjects in Japan. International journal of yoga, 4(1), 7.

Guzicki, J. A. (1984). The Effects Of Cue-controlled Relaxation and Stress Inoculation in Reducing Teacher Anxiety (Order No. 8601443). Available from ProQuest Dissertations \& Theses Global. (303371972). Retrieved from https://search.proquest.com/docview/303371972?accountid=47253

Harmon-Bowman, M. (1981). Stress Inoculation Training: The Effect of Self-efficacy And Education Treatment on Trainee Performance (Order No. 8114955). Available from ProQuest Dissertations \& Theses Global. (303148743).

Health and Safety Executive (2018, October 31). Work-related stress depression or anxiety statistics in Great Britain, 2018. Retrieved from: http://www.hse.gov.uk/statistics/causdis/stress.pdf

Hendrickson, M. E. (1983). The Effects Of Stress Inoculation Training On Migraine Headaches (Order No. 8407482). Available from ProQuest Dissertations \& Theses Global. (303277851).

Hersen, M. (2005). Encyclopedia of Behavior Modification and Cognitive Behavior Therapy, Volume 1. In M. Hersen \& J. Rosqvist, editors. Sage Publication Inc. California. 
Hoffman, M (2011). Japan needs to do more than simply 'cope' with stress

Hourani, L., Tueller, S., Kizakevich, P., Lewis, G., Strange, L., Weimer, B., ... \& Spira, J. (2016). Toward preventing post-traumatic stress disorder: development and testing of a pilot predeployment stress inoculation training program. Military medicine, 181(9), 1151-1160.

Jimenez, V., Solon, J, \& Surban, D. (2017). Academic Stressors of pre-service teachers. UM Research Congress. Retrieved from http://umindanao.edu.ph/journal/wp-content/uploads/2017/05/2017_Bookof-Abstracts-conference-proceedings_FINAL2.pdf

Johns, R. E. (1986). Occupational Stress Inoculation: The Separate And Combined Effects Of Internal And External Coping Skills Relevant To Correctional Officers At A Maximum Security Prison (Order No. 8615204). Available from ProQuest Dissertations \& Theses Global. (303520459).

Klein, S. (2018). Learning: Principles and Applications. SAGE Publications. Retrieved from: https://books.google.com.ph/books?id=2i5cDwAAQBAJ

Lavit, A. C. (1982). The Effects Of Self-instructional And Stress Inoculation Training On The Frequency Of Aggressive Behavior In Children (Order No. 8214902). Available from ProQuest Dissertations \& Theses Global. (303054624).

Lazarus, R. S., \& Folkman, S. (1984). Stress, appraisal, and coping. New York: Springer.

Lazarus, R. S., \& Folkman, S. (1987). Transactional theory and research on emotions and coping. European Journal of Personality, 1, 141-169.

Malgorzata, M., Schneider, E., Gonzales, E (2009). OSH in figures: stress at work - facts and figures. Retrieved from: https://osha.europa.eu/en/node/6862/file_view

Martinez, K. (2004). Stress and stress vulnerability: A review of the generic stress literature with a developmentally disabled population, towards integration and synchrony (Order No. 3180973). Available from ProQuest Dissertations \& Theses Global. (305075944).

McClellan, S., \& Hamilton, B. (2009). The Ultimate Stress-Relief Plan for Women. Simon and Schuster.

McCordick, S. M., Kaplan, R. M., Finn, M. E., \& Smith, S. H. (1979). Cognitive behavior modification and modeling for test anxiety. Journal of Consulting and Clinical Psychology, 47(2), 419.

McDaid, P. K. (2007). The effects of stress inoculation training on the anxiety-related challenging behavior of middle school students with Asperger's syndrome (Order No. 3259856). Available from ProQuest Dissertations \& Theses Global. (304897676).

Meichenbaum, D. H., \& Deffenbacher, J. L. (1988). Stress inoculation training. The Counseling Psychologist, 16(1), 69-90.

Meichenbaum, D.H. (2008). Stress Inoculation Training. In W. O'Donohue \& J. Fisher. Cognitive Behavior Therapy: Applying Empirically Supported Techniques in Your Practice. Wiley \& Sons Inc. New Jersy.

Moses, A. N., III. (1980). Stress Inoculation: An Analysis of the Relative Contribution of the Educational Component on the Reduction of Dental Anxiety (Order No. 8109885). Available from ProQuest Dissertations \& Theses Global. (303055729).

Ratanasiripong, P., Ratanasiripong, N., \& Kathalae, D. (2012). Biofeedback intervention for stress and anxiety among nursing students: a randomized controlled trial. ISRN nursing, 2012.

Rosmith, E. S. (2013). Mental toughness training for police officers: The impact of a stress inoculation program on police stress (Order No. 3691078). Available from ProQuest Dissertations \& Theses Global. (1667457569).

Sadigh, M.R. (2012). Autogenic Training: A Mind-Body Approach to the Treatment of Chronic Pain Syndrome and Stress-Related Disorders. McFarland Health Topics. In Elaine Moore. $2^{\text {nd }}$ Edition. McFarland. North Carolina, USA.

Saunders, T., Driskell, J. E., Johnston, J. H., \& Salas, E. (1996). The effect of stress inoculation training on anxiety and performance. Journal of occupational health psychology, 1(2), 170.

Sax, S. H. (1990). The effect of psychological intervention upon stress associated with hyperbaric oxygen treatment (Order No. 9031245). Available from ProQuest Dissertations \& Theses Global. (303874526). 
Schmidt, D. L. (1982). Enhancement of Tolerance for Pain: Group versus Individual Stress Inoculation Training (Order No. 8128183). Available from ProQuest Dissertations \& Theses Global. (303057802).

Serrano, A. (1993). The effects of a self-directed stress inoculation training program on selected psychological and physiological measures related to anxiety in collegiate volleyball players (Order No. 9318527). Available from ProQuest Dissertations \& Theses Global. (304051725).

Simmons, J. C. (1993). The effects of stress inoculation training on managing stress of first-year law students (Order No. 9323120). Available from ProQuest Dissertations \& Theses Global. (304051444).

Spielberger, C. (1972). "Anxiety as an emotional state." In Anxiety: current trends in theory and research, Vol. 1 Charles D., Spielberger (Ed.). New York: Academic Press.

Spielberger, C. D. (1966). Theory and research on anxiety. Anxiety and behavior. New York: Academic Press.

Spielberger, C. D. (1983). State-Trait Anxiety Inventory for Adults Manual, Instrument, and Scoring Guide. MindGarden Inc.

Suinn, R.M. (2013). Anxiety Management Training: A Behavior Therapy. Springer Science \& Business Media. (376 pp). Retrieved from https://books.google.com.ph/books?id=vfYHCAAAQBAJ\&pg

Toloczko, A. M. (1989). The effects of social support training and stress inoculation training on burnout in nurses (Order No. 8921645). Available from ProQuest Dissertations \& Theses Global. (303791772).

Tomacruz, S. (2018, September 11). A cry for help: Mental illness, suicide cases rising among youth. Rappler. Retrieved from: https://www.rappler.com/newsbreak/in-depth/211671-suicide-cases-mentalhealth-illness-youth-rising-philippines

Turner, M., \& Barker, J. B. (2013). Examining the efficacy of rational-emotive behavior therapy (REBT) on irrational beliefs and anxiety in elite youth cricketers. Journal of Applied Sport Psychology, 25(1), 131-147.

Velasco, B. (2013, May 25). New studies on stress. Philippines Star. https://www.philstar.com/sports/2013/05/25/946128/new-studies-stress

Warden, M. F. (1983). The Significance of Two Methods of Stress Management for Surgical Patients (Order No. 8311665). Available from ProQuest Dissertations \& Theses Global. (303120193).

West, D. J.(1982). Occupational Stress-inoculation: An Experimental Application On Registered Nurses In An Acute Care Hospital Setting (Order No. 8213361). Available from ProQuest Dissertations \& Theses Global. (303238855).

Yepes, E. (1984). A Comparison Of Stress Inoculation Training And Diabetes Education In The Management Of Type l-insulin Dependent Diabetes Mellitus (stress Management, Placebo Effect) (Order No. 8500541). Available from ProQuest Dissertations \& Theses Global. (303304455). 